\title{
Derivation and growth characteristics of dental pulp stem cells from patients of different ages
}

\author{
WEI WU, JIAN ZHOU, CHONG-TAO XU, JIE ZHANG, YAN-JIAO JIN and GENG-LIN SUN \\ Department of Stomatology, Tianjin Medical University General Hospital, Tianjin 300052, P.R. China
}

Received May 24, 2014; Accepted March 20, 2015

DOI: $10.3892 / \mathrm{mmr} .2015 .4106$

\begin{abstract}
The dental pulp contains a relatively low number of stem cells; however, it is considered to be a promising source of stem cells for use in regenerative therapy. To date, it has remained elusive whether there are certain differences in the dental pulp stem cells (DPSCs) from donors of different ages. In the present study, DPSC lines were derived using teeth from children, adolescents, adults and aged donors. The derivation efficiency, the proliferative and apoptotic rate, cell marker expression and the differentiation capacity were investigated and compared among these DPSC lines. The derivation efficacy was decreased with increasing donor age. Although a large part of cell surface markers was expressed in all DPSC lines, the expression of CD29 was downregulated in the DPSCs from aged teeth. In addition, the doubling time of DPSCs from aged teeth was prolonged and the number of apoptotic cells was increased with the propagation. These DPSCs were able to differentiate into a neuronal linage, which positively expressed the neuron-specific class III beta-tubulin and microtubule-associated protein 2 , as well as into an osteogenic lineage, which positively expressed CD45; however, these DPSCs from aged teeth were completely or partially deprived of differentiation capacity. By contrast, DPSCs from younger teeth displayed significantly higher vitality and a higher potential for use in dental regenerative medicine.
\end{abstract}

\section{Introduction}

Human teeth are highly specialized organs of the human body. Two series of teeth grow in humans comprised of 20 temporary teeth and 32 permanent teeth; however, the second series of teeth hardly show any further growth following their maturation. If the teeth are broken through physical impact, bacterial degradation or aging factors in adults, they are not

Correspondence to: Dr Wei Wu, Department of Stomatology, Tianjin Medical University General Hospital, 154 Anshan Road, Tianjin 300052, P.R. China

E-mail: wuweizyy@126.com

Key words: dental pulp stem cells, age, growth characteristics, cell marker, differentiation able to regenerate and are currently replaced with artificial prosthetics or implants (1). However, regenerative medicinal studies are currently investigating the feasibility of tooth regeneration using stem cells, and therefore, it is important to study development mechanisms of human teeth for further tooth regeneration (2).

Pluripotent stem cells have been isolated from embryos or various tissues, and they have displayed tremendous potential in regenerative medicine due to their characteristics of self-renewal and multi-differentiation under certain conditions. In 2000, Gronthos et al (3) isolated cells from the dental pulp of odontogenic teeth and proved the characteristics of self-renewal and potency for multilineage differentiation of these cells, and finally named these cells as dental pulp stem cells (DPSCs) (3). The discovery of DPSCs provided the tool to study mechanisms of dental development.

In the past ten yeas, studies on DPSCs have led to the development of isolation and culturing techniques. Miura et al (4) successfully isolated stem cells from human exfoliated deciduous teeth (SHED) and identified that they had the general characteristics of DPSCs. Wang et al (5) also isolated SHED and found that their capability of mineralization and mRNA expression levels of inflammatory cytokines were higher compared with those of DPSCs (5). Furthermore, Kerkis and Caplan (6) described that the derivation of induced pluripotent stem (iPS) cells from DPSCs was significantly more efficient compared with that of human fibroblasts. In addition, stem cells from the third molar were shown to have a lower population doubling time, higher colonogenic activity and an improved growth curve compared with those from the deciduous incisor, indicating that stem cells from the human third molar are appropriate candidates for use in experimental, pre-clinical and even clinical setups (7). However, a study by Govindasamy et al (8) indicated that the proliferation rate of the stem cells derived from human deciduous teeth was higher than that from human permanent teeth. Furthermore, stem cells from deciduous and permanent teeth display differences in their differentiation ability, particular into neuronal lineages, as well as differential expression of extracellular matrix proteins that are involved in the odontoblast lineage differentiation and in dentin mineralization $(9,10)$.

Although these differences in proliferation and gene expression between stem cells from deciduous and permanent teeth have been identified, the reasons accounted to these differences have remained elusive. Studies on adult stem 
cells have provided conflicting information, with certain studies reporting no change (11-14) while others identified an age-associated decline of the above-mentioned parameters (15). It is not known whether aging of DPSCs affects their differentiation ability, but the donor age for deciduous stem cells is always less than that for permanent stem cells; however, there is still no detailed study on the effects of donor age on the DPSCs.

In addition, expression of cell surface maker genes varied in adult stem cells from different tissues, except for a number of pluripotent stem cell marker genes. Abramova et al (16) proved that gene expression was dependent on the embryonal development stage in acutely isolated central nervous system progenitor cells from mice. In long-term cultured mesenchymal stem cells (MSCs), Halfon et al (17) found that cell surface marker genes were downregulated with increasing passage and indicated its close association with the quality of MSCs. However, although certain cell surface marker genes were shown to be differentially expressed under different conditions, the effect of the donor age on marker gene expression on DPSCs has remained elusive.

The present study aimed to investigate the derivation of DPSCs from human teeth of donors of different age and compared cell surface marker gene expression among them. The teeth were assessed regarding the presence of stem cells, and the latter were examined for their potential to proliferate, differentiate and to be used in regenerative dental medicine.

\section{Materials and methods}

Isolation and culture of DPSCs. The present study was approved by the ethics committees of Tianjin University and Tianjin General Hospital (Tianjin, China). Human dental pulp tissues were obtained from clinically healthy extracted deciduous and permanent teeth (due to trauma), including six deciduous teeth from children aged 4-8 years, four permanent teeth from adolescents aged 12-20 years, five permanent teeth from adults aged 30-50 years and six permanent teeth from aged individuals aged 55-67 years. The DPSCs were isolated and cultured as previously described (18). The teeth were fractured with a dental surgical elevator (model:1141-1; Rongwei Ltd. Corp., Shanghai, China) and pulp tissue was gently separated with a sterile dentinal excavator (Gladent; Henki Medical Instrument Factory, Foshan, China) from the crown and root. The dental pulp was gently rinsed in phosphate-buffered saline (PBS; Thermo Fisher Scientific, Inc., Waltham, MA, USA), dissected into 1- $\mathrm{mm}^{2}$ tissue sections and implanted into culture dishes (BD Biosciences, New York, NY, USA) in $3 \mathrm{ml}$ culture medium. After three to four days, soma fibroblast-like cells grew around the mass and were digested with $0.5 \mathrm{~g} / 1$ trypsin and $0.53 \mathrm{mmol} / 1$ EDTA (both Thermo Fisher Scientific, Inc.) for 3-5 $\mathrm{min}$ at $37^{\circ} \mathrm{C}$. The fibroblast-like cells were further incubated for propagation and later passaged at $\sim 5 \times 10^{4}$ cells $/ \mathrm{cm}^{2}$. Cells were incubated at $37^{\circ} \mathrm{C}$ under $5 \% \mathrm{CO}_{2}$ and $80 \%$ humidity. Penicillin and streptomycin (Thermo Fisher Scientific, Inc.) were used in all solutions to minimize bacterial contamination.

Cell proliferation analysis. The cell number was quantified using a Scepter Handheld automated cell counter with $60-\mu \mathrm{m}$
Scepter Sensors (both Merck-Millipore, Billerica, MA, USA), which employs the Colter principle of impedance-based particle detection. The concentration of viable cells was identified based on cell volume/size measurements using Scepter software Pro 2.0 (Merck-Millipore).

Fluorescence-activated cell sorting (FACS) analysis. Cell surface marker expression was analyzed by FACS. Briefly the cells of the different cell lines were digested using $0.25 \%$ trypsin and then rinsed with PBS. The harvested cells were stained with the monoclonal antibodies for overnight and analyzed by FACSAria II (BD Biosciences, San Jose, CA, USA). The following antibodies were used: CD14-fluorescein isothiocyanate (FITC), CD29-phycoerythrin (PE), CD31-PE, CD34-PE, CD44-PE, CD73-PE, CD90-allophycocyanine (APC), CD166-PE, CD45-PerCP-Cy5, HLA-DR-PerCP-Cy5, CD105-PE and CD133-APC.

DPSC differentiation in vitro. The DPSCs were stimulated to differentiate in vitro into neuronal cells and osteoblasts according to previous methods $(19,20)$. For neuronal differentiation, the DPSCs were cultured in a specific induction medium [Dulbecco's modified Eagle's medium-high glucose, 10\% fetal bovine serum (FBS), $5 \mathrm{ml} / 1$ B27 supplemented with $10 \mathrm{ng} / \mathrm{ml}$ epidermal growth factor and $20 \mathrm{ng} / \mathrm{ml}$ basic fibroblast growth factor; Thermo Fisher Scientific, Inc.] for the first 15 days, and then the cells were transferred into the second differentiation medium supplemented with neuronal growth factors [10 $\mathrm{ng} / \mathrm{ml}$ neurotrophin- $3,10 \mathrm{ng} / \mathrm{ml}$ nerve growth factor, $25 \mathrm{ng} / \mathrm{ml}$ brain-derived neurotrophic factor (BDNF), $10 \mathrm{mM}$ butylated hydroxyanisole, $25 \mathrm{mM}$ 3-isobutyl-1-methylxanthine (IBMX), $0,5 \mathrm{mM}$ all-trans retinoic acid and $10 \mathrm{nM}$ progesterone; Thermo Fisher Scientific, Inc.] for another 15 days, and finally, the differentiated cells were incubated in the third differentiation medium supplemented with $50 \mathrm{ng} / \mathrm{ml}$ BDNF; $5 \mathrm{mg} / \mathrm{ml}$ insulin; $200 \mathrm{mM}$ indomethacin and 0.5 mM IBMX (all Thermo Fisher Scientific, Inc.) for one day. The differentiated neuronal cells were identified by immunofluorescence.

For osteogenic differentiation, the DPSCs were cultured in differentiation medium consisting of $\alpha$-minimum essential medium supplement with $10 \%$ FBS, $10 \mathrm{nM}$ dexamethasone, $10 \mathrm{mM}$ b-glycerophosphate (Thermo Fisher Scientific, Inc.) and $100 \mathrm{mM}$ Sigma A-7506 L-ascorbate-2-phosphate (Sigma-Aldrich, St. Louis, MO, USA). After 20 days, mineralized deposits were observed in the culture medium and identified by reverse transcription polymerase chain reaction (RT-PCR).

Immunofluorescence analysis of cells. The DPSCs and the differentiated cells were collected, fixed with $4 \%$ paraformaldehyde and then permeabilized with $0.25 \%$ Triton X-100 (all Thermo Fisher Scientific, Inc.). At passage 10, the cells were blocked and stained with the primary antibody [anti-microtubule-associated protein 2 (MAP2) or anti-neuron-specific class III beta-tubulin (TUJ1)] overnight at $4^{\circ} \mathrm{C}$ followed by the appropriate secondary antibodies detecting mouse and rabbit immunoglobulin G, respectively. The sample was then rinsed three times using PBS and dried at room temperature. A cover slip was placed on the sample and the slide was observed under a confocal microscope (LSM 510; Zeiss, Oberkochen, Germany) and images were captured. 
Table I. Information on established human dental pulp stem cell lines.

\begin{tabular}{|c|c|c|}
\hline Donor age (years) & DPSCs & $\begin{array}{r}\text { Derivation } \\
\text { efficiency }(\%)\end{array}$ \\
\hline \multicolumn{3}{|l|}{ Children $(n=6)$} \\
\hline 4 & $\mathrm{Y}$ & 100.0 \\
\hline 6 & Y & \\
\hline 5 & $\mathrm{Y}$ & \\
\hline 5 & $\mathrm{Y}$ & \\
\hline 8 & $\mathrm{Y}$ & \\
\hline 4 & $\mathrm{Y}$ & \\
\hline \multicolumn{3}{|l|}{ Adolescents (n=4) } \\
\hline 15 & Y & 100.0 \\
\hline 12 & $\mathrm{Y}$ & \\
\hline 16 & $\mathrm{Y}$ & \\
\hline 20 & $\mathrm{Y}$ & \\
\hline \multicolumn{3}{|l|}{ Adults (n=5) } \\
\hline 33 & $\mathrm{Y}$ & 60.0 \\
\hline 38 & $\mathrm{~N}$ & \\
\hline 45 & $\mathrm{~N}$ & \\
\hline 32 & $\mathrm{Y}$ & \\
\hline 49 & $\mathrm{Y}$ & \\
\hline \multicolumn{3}{|l|}{ Aged $(n=6)$} \\
\hline 62 & $\mathrm{~N}$ & 33.3 \\
\hline 63 & $\mathrm{Y}$ & \\
\hline 55 & $\mathrm{Y}$ & \\
\hline 62 & $\mathrm{~N}$ & \\
\hline 67 & $\mathrm{~N}$ & \\
\hline 59 & $\mathrm{~N}$ & \\
\hline Total $(\mathrm{n}=21)$ & 15 & 71.4 \\
\hline
\end{tabular}

DPSCs, dental pulp stem cells; Y, yes; N, no (establishment of the cell line was attempted, but not successful).

Karyotype analysis. Karyotype analysis (G-banding) was performed on at least 20 cells from each sample. The cells were harvested and centrifuged (speed, $300 \mathrm{x}$ g for $5 \mathrm{mins}$ at room temperature) following colchicine treatment, and the cells were then re-suspened in $70 \mathrm{mM} \mathrm{KCl}$ (Sigma-Aldrich) for $20 \mathrm{~min}$ at $37^{\circ} \mathrm{C}$, and then centrifuged again (as above). The cells were fixed with methanol/acetic acid (3:1) for $5 \mathrm{~min}$ at room temperature. The cells were centrifuged again (as above) and the cell pellet was incubated overnight at $4^{\circ} \mathrm{C}$. The cells were finally placed on a glass slide and stained with Giemsa solution (Sigma-Aldrich).

$R T-P C R$. Cells were harvested using trypsin. After washing with PBS, mRNA was isolated by using an RNeasy Miniprep kit (Qiagen,Hilden,Germany).Reversetranscriptionwasperformed using an Invitrogen SuperScript First-strand Synthesis System kit (Invitrogen Life Technologies, Carlsbad, CA, USA). The following primer pairs were used to detect the gene-specific mRNAs: Forward, 5'-GAGCAAAACCCGGAGGAGT-3' and reverse, 5'-TTCTCTTTCGGGCCTGCAC-3' for human Oct4.

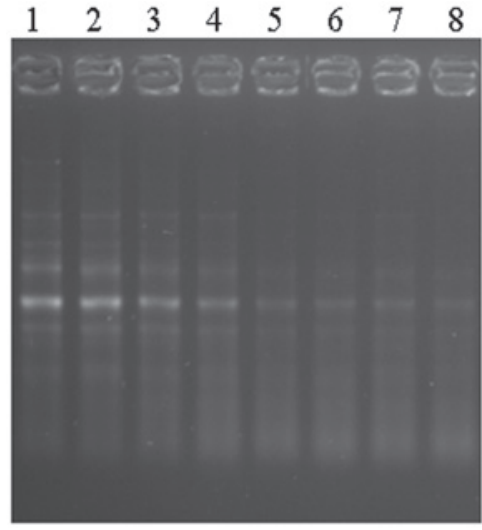

Figure 1. Oct4 expression in human embryonic stem cells and dental pulp stem cells. Lanes: 1 and 2, human embryonic stem cells; 3 and 4, dental pulp stem cells from children; 5 and 6, dental pulp stem cells from adolescents; 7 , dental pulp stem cells from adults; 8 , dental pulp stem cells from aged donors.

A Mastercycler nexus (Eppendorf Ltd., Hamburg, Germany), was used and PCR was performed for 35 cycles. Quantification of PCR products was performed using a JY-SCZ2 electrophoresis chamber (Junyidongfang Ltd., Beijing, China) with A-6013 agarose (Sigma-Aldrich).

Measurement of apoptotic cells. Call apoptosis was measured at passage 10. The cells were harvested and suspended in Annexin V-binding buffer (BioVision Inc., Milpitas, CA, USA). Annexin V-FITC (BioVision) was added to the cell suspensions, which were incubated at room temperature for 5 min in the dark. The suspensions were analyzed using a FACSAria cell sorter.

Statistical analysis. Cell growth/proliferation and apoptosis assay was repeated three times. Values are expressed as the mean \pm standard deviation. Statistical analysis was performed using one-way analysis of variance with Bonferroni's post hoc test. $\mathrm{P}<0.05$ was considered to indicate a statistically significant difference between values. Data were analyzed using SPSS 13.0 software (SPSS, Inc., Chicago, IL, USA).

\section{Results}

A total of six DPSC lines were derived from deciduous teeth of six children, four DPSC lines were derived from permanent teeth of four adolescents, three DPSC lines were derived from five permanent teeth from adults and two DPSC lines were derived from six permanent teeth from aged donors. The derivation efficiency was decreased with increasing donor age (Table I).

The derived DPSCs were identified by specific marker gene expression. The pluripotent transcript factor Oct 4 was positively expressed in all of the DPSC lines from donors of different age (Fig. 1). The results of FACS analysis indicated that the specific cell surface markers (CD13, CD29, CD59 and CD146; Fig. 2A-D, respectively) were positively expressed and negative makers (CD19, CD24 and CD45; Fig. 3A-C, respectively) could not be observed in the DPSC lines. However, the expression intensity of CD29 was decreased with the propagation until 
A
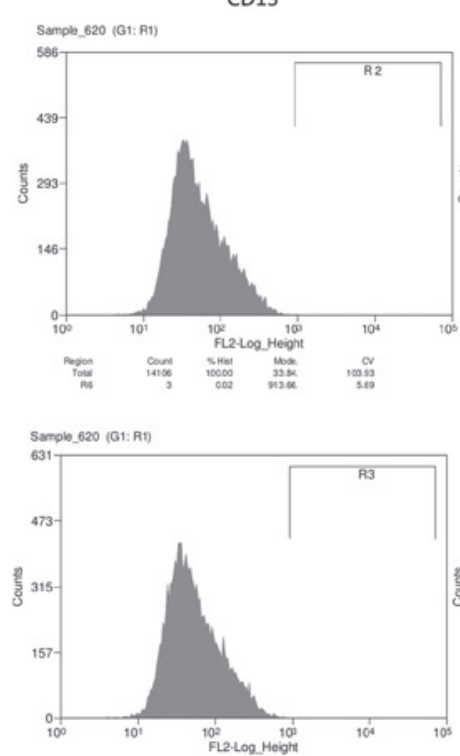

B
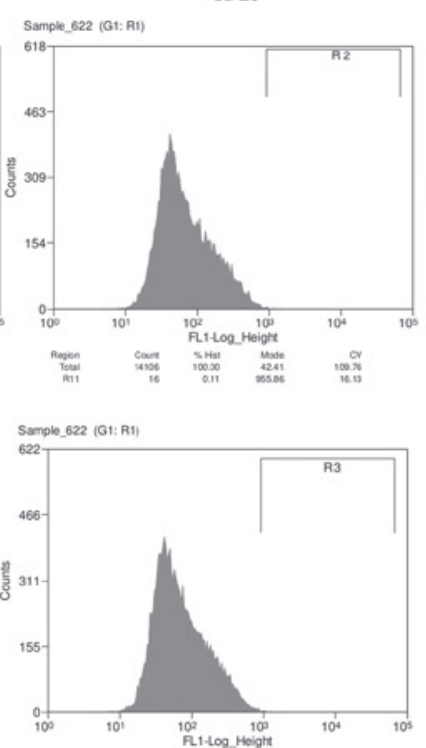

C
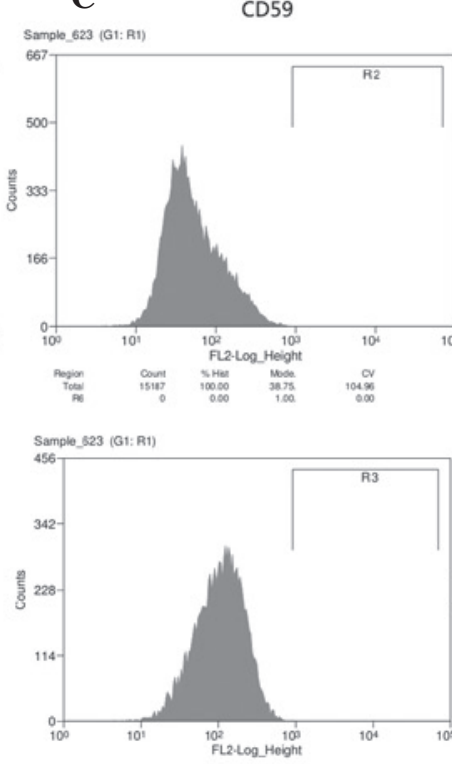

D

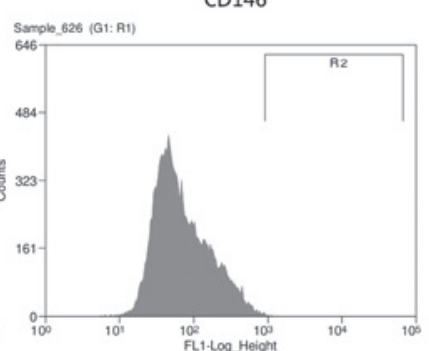

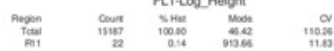

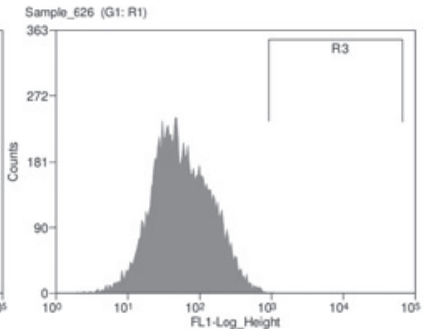

Figure 2. Identification of human dental stem cell-positive markers. (A) CD13; (B) CD29; (C) CD59; and (D) CD146. Top row, aged donors; bottom row, children.

$\mathbf{A}$
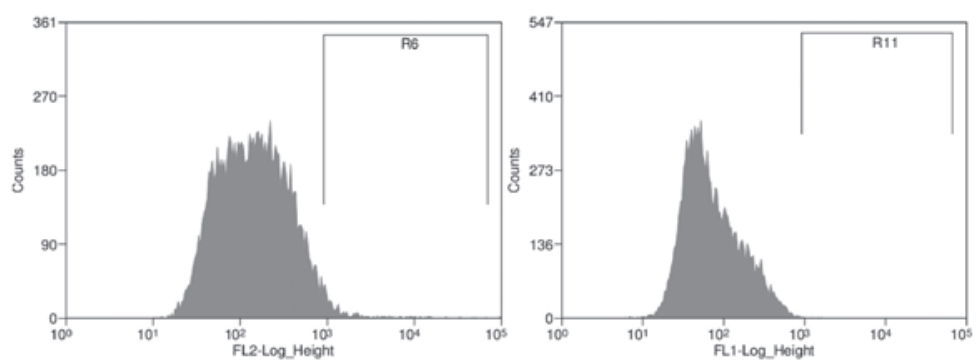

B
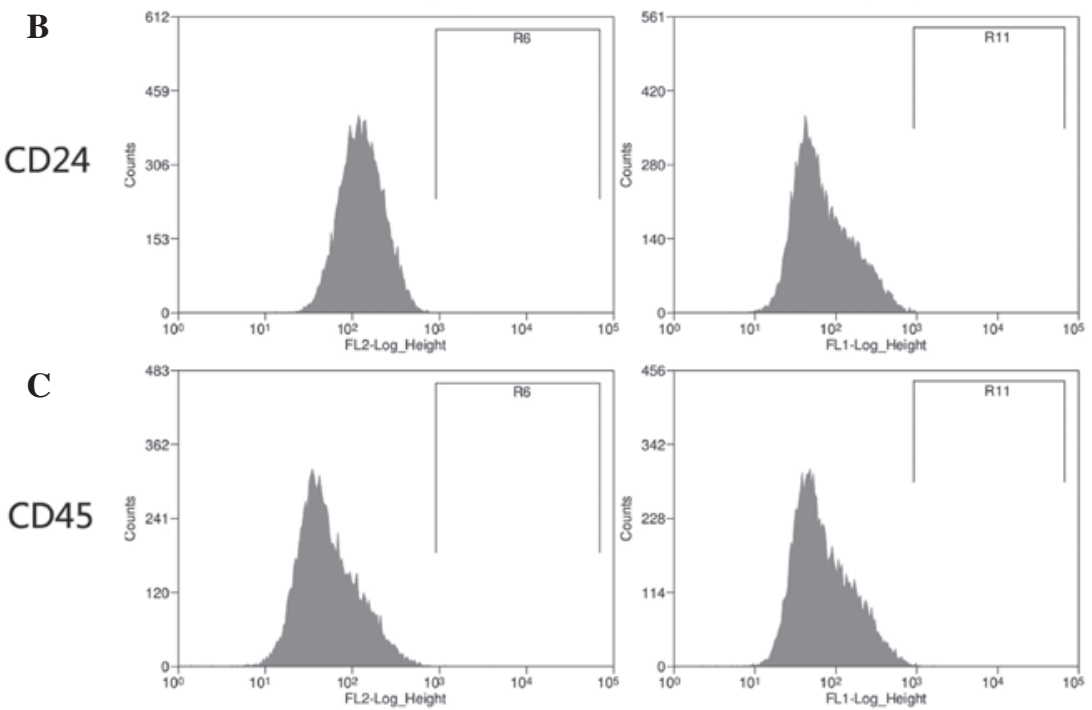

D
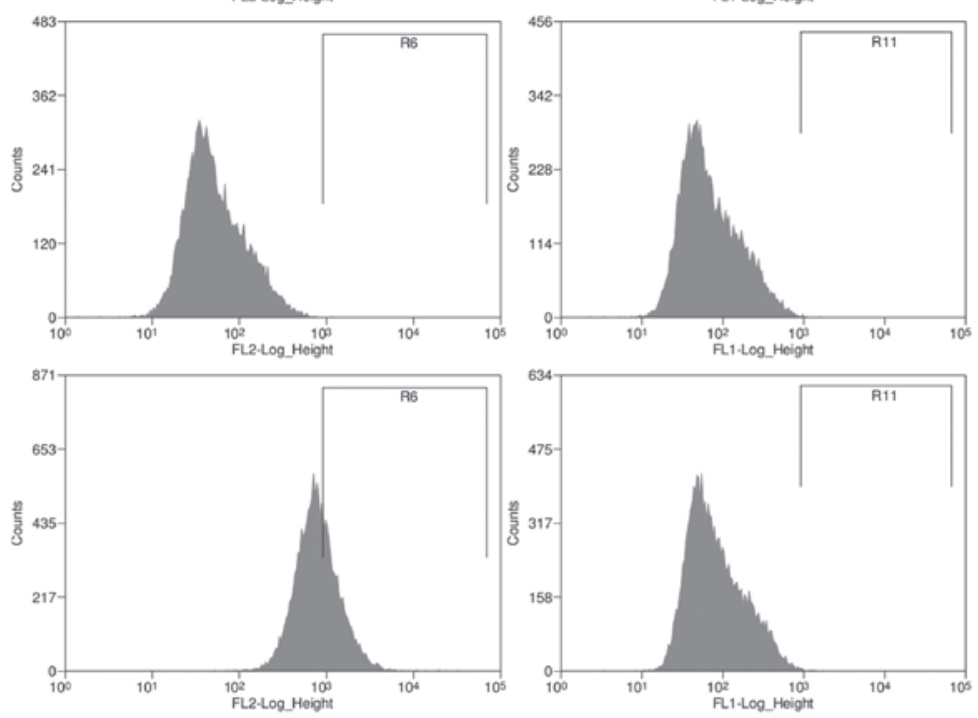

Figure 3. Identification of human dental stem cell-negative markers. (A) CD19, (B) CD24, (C) CD45 and (D) CD29 expression was decreased with the propagation of human dental stem cells from aged teeth. (A-C) Left row, aged donors; right row, children. (D) Left row, decreased CD29 expression in passage 10 of DPSC from aged donor; right row, normal CD29 expression in passage 5 of DPSC from aged donor. DPSCs, dental pulp stem cells. 

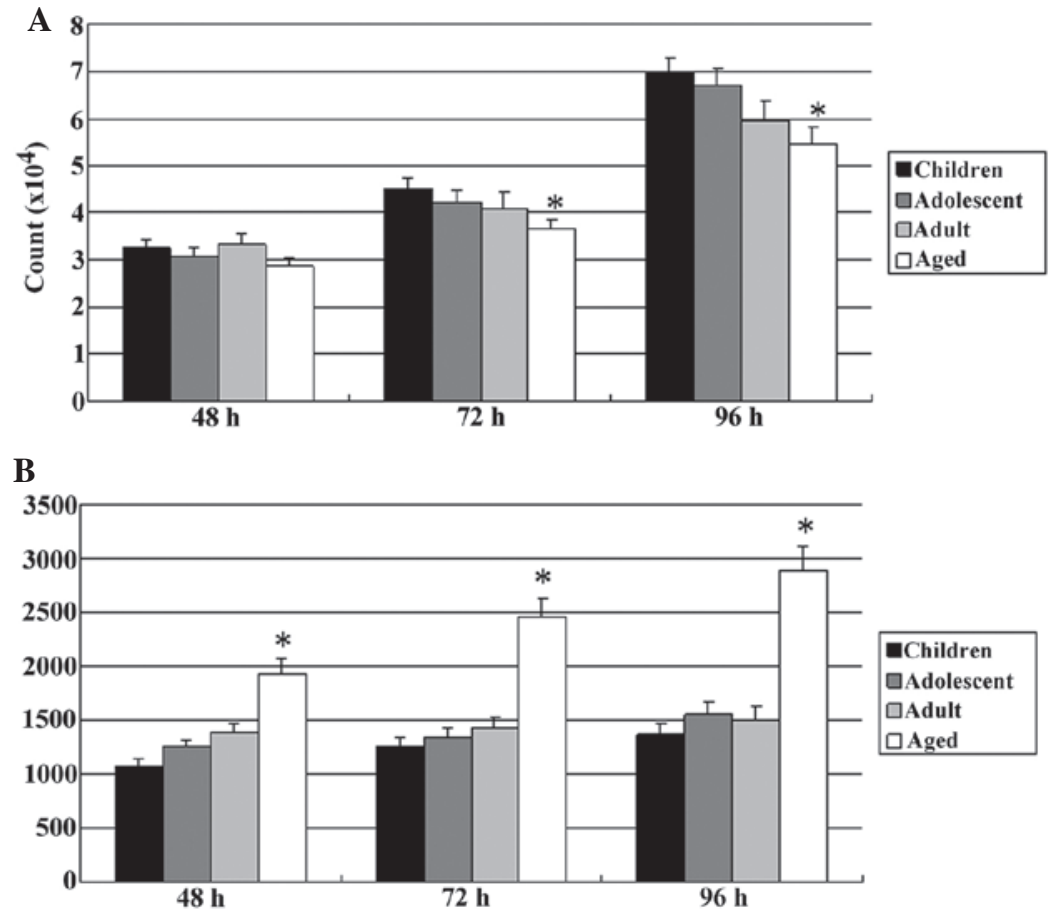

Figure 4. Effects of donor age on the proliferation and apoptosis of dental stem cells. Data are presented as the mean \pm standard error of the mean. (A) The proliferation rate was not significantly different among children, adolescent and adult groups, but was significantly decreased in the dental stem cells from aged donors. (B) Apoptotic cell number was significantly increased in the human dental stem cells from aged donors compared with that in the other three groups.
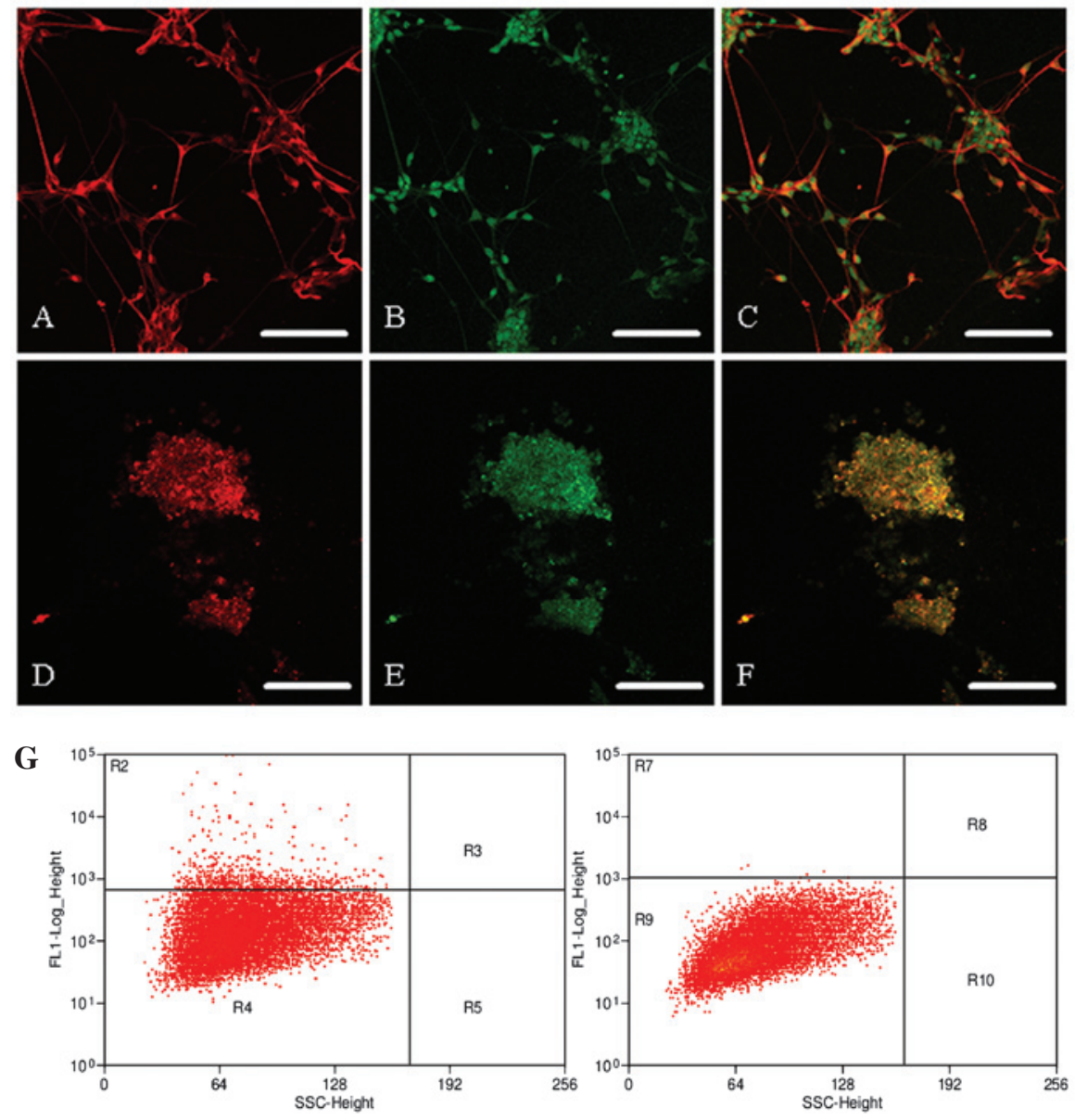

Figure 5. Identification of neuronal and osteogenic lineage differentiation of human dental stem cells. (A-F) Representative images for adult dental pulp stem cells. (A) MAP2 expression indicating neuronal differentiation; (B) nuclear staining; (C) merged image; (D) TUJ-1 expression indicating neuronal differentiation; (E) nuclear staining; (F) merged image; (G) CD45 expression of osteogenic lineage differentiation. MAP, microtubule-associated protein; TUJ-1, neuron-specific class III $\beta$-tubulin. 
passage ten in the DPSCs from permanent teeth of aged donors (Fig. 3D).

The proliferation of DPSCs in each group was evaluated at 48, 72, and $96 \mathrm{~h}$. There were no differences among the DPSCs in the four age groups at $48 \mathrm{~h}$, but at $72 \mathrm{~h}$, the proliferation rate of DPSCs from aged donors was significantly lower than that in the other three groups. Furthermore, at $96 \mathrm{~h}$, the proliferation rate of DPSCs from aged donors was significantly decreased, and the proliferation rate of DPSCs from adult donors was also significant lower than that of the DPSCs from deciduous teeth of children and permanent teeth from adolescents (Fig. 4A). Furthermore, as shown in Fig. 4B, the population of annexin V-positive (apoptotic) cells was increased in the DPSCs from aged donors at $48 \mathrm{~h}$, and the apoptotic cells were continuously increased later at 72 and $96 \mathrm{~h}$, whereas the population of annexin V-positive cells did not increase in the other groups.

All of the DPSC lines from deciduous teeth of children and permanent teeth of adolescents were able to differentiate into neuronal and osteogenic lineages under the specific differentiation conditions. However, one DPSC line from adult permanent teeth was not able to differentiate into an osteogenic lineage, but into neurons, while two other DPSC lines from adult permanent teeth were able to undergo neuronal and osteogenic differentiation. Furthermore, one DPSC line from the tooth of an aged donor differentiated into an osteogenic lineage but did not undergo neuronal differentiation, while the other one could not be induced to differentiate at all (Table II). Differentiation was confirmed using the neuronal markers MAP2 and TUJ-1 (Fig. 5A-F) and the bone marker CD45 (Fig. 5G).

\section{Discussion}

In the present study, DPSCs were successfully isolated from deciduous or permanent teeth from donors of different ages, and these cells were positive for DPSCs-specific markers alongside typical morphologies (adherent cells resembling fibroblasts) (21). However, the expression of certain marker genes was decreased and the differentiation to neuronal and osteogenic lineages was also impaired in the DPSCs from permanent teeth of aged donors compared with those in the other three groups.

DPSCs have been derived from deciduous teeth of children and permanent teeth of adults; however, there are few studies on DPSCs derived from permanent teeth of aged individuals (22). In the permanent teeth of aged individuals, the cell number in the dental pulp is reduced, and the fiber as well as the collagen composition is gradually increased (23). Furthermore, calcification often occurs in parts of the pulp chamber and root canal, which results in a reduction in size of the pulp chamber caused by the continual secretion of dentin matrix by odontoblasts (24). Mitsiadis et al (25) showed that the dental pulp volume decreases gradually upon aging due to the continuous production of dentin matrix by odontoblasts and that this age-associated pulp chamber reduction is due to the elimination of a certain number of odontoblasts by apoptosis. These age-associated physiological changes explain, at least in part, the lower efficiency of DPSC line derivation from permanent teeth of aged donors.

The DPSC proliferation rate was analyzed and the results indicated that high donor age impaired the proliferation rate. The possible explanation for this was the increasing levels of apoptosis in DPSCs from teeth of aged donors. In the present
Table II. Differentiation ability of human DPSCs.

\begin{tabular}{lcc}
\hline DPSC lines & Neuronal lineage & Osteogenic lineage \\
\hline Child-1 & $\mathrm{Y}$ & $\mathrm{Y}$ \\
Child-2 & $\mathrm{Y}$ & $\mathrm{Y}$ \\
Child-3 & $\mathrm{Y}$ & $\mathrm{Y}$ \\
Child-4 & $\mathrm{Y}$ & $\mathrm{Y}$ \\
Child-5 & $\mathrm{Y}$ & $\mathrm{Y}$ \\
Child-6 & $\mathrm{Y}$ & $\mathrm{Y}$ \\
Adolescent-1 & $\mathrm{Y}$ & $\mathrm{Y}$ \\
Adolescent-2 & $\mathrm{Y}$ & $\mathrm{Y}$ \\
Adolescent-3 & $\mathrm{Y}$ & $\mathrm{Y}$ \\
Adolescent-4 & $\mathrm{Y}$ & $\mathrm{Y}$ \\
Adult-1 & $\mathrm{Y}$ & $\mathrm{Y}$ \\
Adult-2 & $\mathrm{Y}$ & $\mathrm{N}$ \\
Adult-3 & $\mathrm{Y}$ & $\mathrm{Y}$ \\
Elderly-1 & $\mathrm{N}$ & $\mathrm{Y}$ \\
Elderly-2 & $\mathrm{N}$ & $\mathrm{N}$ \\
\hline
\end{tabular}

Y, yes; N, no; DPSC, dental pulp stem cell.

study, a significantly higher apoptotic rate was observed in aged DPSCs using annexin V staining. Apoptosis is expected to decrease the mitotic cell number, resulting in a decreased proliferation rate; furthermore, age-associated DNA replication errors and reduced genomic stability are observed in aged cells, leading to induction of apoptosis and a reduced proliferation rate. The activation of apoptotic signaling pathways in aged dental pulp has been proved by Tranasi et al (26) using a microarray method.

Furthermore, DPSC-specific cell surface marker gene expression was identified in the present study. The transcription factor Oct4, which is specifically expressed in pluripotent stem cells, was positively expressed in all DPSC lines, and a number of DPSC-specific cell surface markers were also positively or negatively expressed as expected in the DPSCs, which proved the DPSCs originated from dental pulp and not from MSCs (27-29). A study observed changes in MSC-specific marker expression and epigenetic modification following long-term culture in vitro (30). In the present study, CD29 expression was decreased at the tenth passage in the DPSCs from permanent teeth of aged donors, but not differently expressed in DPSCs derived from teeth of the other age groups, suggesting that the donor age contributed to the differential gene expression profiling for specific markers. Similar results were obtained for human bone marrow mesenchymal stem cells by Zaim et al (31). A study by Pruszak et al (32) indicated that CD29 together with CD15 and CD24 was able to regulate neuronal differentiation and proved that low expression of CD29 reduced the population of proliferating cell types in human embryonic stem cell differentiation. The distinct function of CD29 was associated with $\beta 1$-integrin signaling and regulatory cell adhesion by interacting with the extracellular matrix (ECM), whereas integrin signaling has been shown to be of functional relevance for neural crest (33) as well as mesenchymal development $(34,35)$. Tranasi et al (26) 
identified several differentially expressed genes that were categorized as growth factors, transcription regulators, apoptosis regulators and genes of the ECM using a high-throughput microarray method, and indicated that in dental pulp from young individuals, biological functions of cells, including tissue differentiation and development as well as proliferation and of immune, lymphatic and hematologic cells were exerted at high rates, whereas apoptotic pathways were active in dental pulp from aged donors (26).

CD29 is regarded to be one of the most important cell surface markers in human neuron stem cells (36). In the present study, neither of the two DPSC lines derived from permanent teeth of aged donors were able to differentiate into neuron lineages, which indicated that the neuronal differentiation ability was impaired by the lower expression of CD29. Aanismaa et al (37) demonstrated that DPSC-derived neural progenitor stage cells could be produced, which, however, did not mature further into functional neuronal cells. In the present study, the differentiated cells from DPSCs were positive for specific markers for neurons and gliocytes. In rats, DPSCs were able to differentiate into nestin-positive progenitors, TUJ-1-positive neuronal cells and S100-positive glial cells (38). Furthermore, human postnatal dental pulp cells were demonstrated to be able to differentiate into class III beta tubulin and TUJ-1 positive neuronal cells (39). In addition to neuronal cells, DPSCs were indicated to differentiate into osteoblasts, adipose cells and smooth muscle cells (40-42). In the present study, osteoblast markers were identified in all DPSCs, and only one cell line derived from a permanent tooth of an aged donor failed to form osteoblasts.

In conclusion, DPSC lines were derived from teeth of donors of different age, and the results demonstrated that the derivation efficiency, proliferation rate, differentiation into neuronal lineages and the cell surface marker expression were all impaired in the DPSCs derived from permanent teeth of aged donors. Therefore, DPSCs should be established and stored as early as possible for treatment of dental diseases in aged patients.

\section{References}

1. Aldrigui JM, Jabbar NS, Bonecker M, Braga MM and Wanderley MT. Trends and associated factors in prevalence of dental trauma in Latin America and Caribbean: a systematic review and meta-analysis. Community Dent Oral Epidemiol 42: 30-42, 2014.

2. Liu J, Yu F, Sun Y, Jiang B, Zhang W, Yang J, Xu GT, Liang A and Liu S. Concise reviews: Characteristics and potential applications of human dental tissue-derived mesenchymal stem cells. Stem Cells 33: 627-638, 2015.

3. Gronthos S, Mankani M, Brahim J, Robey PG and Shi S: Postnatal human dental pulp stem cells (DPSCs) in vitro and in vivo. Proc Natl Acad Sci USA 97: 13625-13630, 2000.

4. Miura M, Gronthos S, Zhao M, Lu B, Fisher LW, Robey PG and Shi S: SHED: stem cells from human exfoliated deciduous teeth. Proc Natl Acad Sci USA 100: 5807-5812, 2003.

5. Wang X, Sha XJ, Li GH, Yang FS, Ji K, Wen LY, Liu SY, Chen L, Ding Y and Xuan K: Comparative characterization of stem cells from human exfoliated deciduous teeth and dental pulp stem cells. Arch Oral Biol 57: 1231-1240, 2012.

6. Kerkis I and Caplan AI: Stem cells in dental pulp of deciduous teeth. Tissue Eng Part B Rev 18: 129-138, 2012.

7. Eslaminejad MB, Vahabi S, Shariati M and Nazarian H: In vitro growth and characterization of stem cells from human dental pulp of deciduous versus permanent teeth. J Dent (Tehran) 7: 185-195, 2010.
8. Govindasamy V, Abdullah AN, Ronald VS, Musa S, Ab Aziz ZA, Zain RB, Totey $S$ and Bhonde RR and Abu Kasim NH: Inherent differential propensity of dental pulp stem cells derived from human deciduous and permanent teeth. J Endod 36: 1504-1515, 2010.

9. Harumi Miyagi SP, Kerkis I, da Costa Maranduba CM, Gomes CM, Martins MD and Marques MM: Expression of extracellular matrix proteins in human dental pulp stem cells depends on the donor tooth conditions. J Endod 36: 826-831, 2010.

10. Butler WT: Dentin matrix proteins. Eur J Oral Sci 106: 204-210, 1998

11. Alt EU, Senst C, Murthy SN, Slakey DP, Dupin CL, Chaffin AE, Kadowitz PJ and Izadpanah R: Aging alters tissue resident mesenchymal stem cell properties. Stem Cell Res 8: 215-225, 2012.

12. Asumda FZ and Chase PB: Age-related changes in rat bone-marrow mesenchymal stem cell plasticity. BMC Cell Biol 12: 44, 2011.

13. Scharstuhl A, Schewe B, Benz K, Gaissmaier C, Bühring HJ and Stoop R: Chondrogenic potential of human adult mesenchymal stem cells is independent of age or osteoarthritis etiology. Stem Cells 25: 3244-3251, 2007.

14. Tokalov SV, Gruener S, Schindler S, Iagunov AS, Baumann M and Abolmaali ND: A number of bone marrow mesenchymal stem cells but neither phenotype nor differentiation capacities changes with age of rats. Mol Cells 24: 255-260, 2007.

15. Kretlow JD, Jin YQ, Liu W, Zhang WJ, Hong TH, Zhou G, Baggett LS, Mikos AG and Cao Y: Donor age and cell passage affects differentiation potential of murine bone marrow-derived stem cells. BMC Cell Biol 9: 60, 2008.

16. Abramova N, Charniga C, Goderie SK and Temple S: Stage-specific changes in gene expression in acutely isolated mouse CNS progenitor cells. Dev Biol 283: 269-281, 2005.

17. Halfon S, Abramov N, Grinblat B and Ginis I. Markers distinguishing mesenchymal stem cells from fibroblasts are downregulated with passaging. Stem Cells Dev 20: 53-66, 2011.

18. Jo YY, Lee HJ, Kook SY, Choung HW, Park JY, Chung JH, Choung YH, Kim ES, Yang HC and Choung PH: Isolation and characterization of postnatal stem cells from human dental tissues. Tissue Eng 13: 767-773, 2007.

19. Yao S, Pan F, Prpic V and Wise GE: Differentiation of stem cells in the dental follicle. J Dent Res 87: 767-771, 2008.

20. Zhang W, Walboomers XF, Shi S, Fan M and Jansen JA: Multilineage differentiation potential of stem cells derived from human dental pulp after cryopreservation. Tissue Eng 12: 2813-2823, 2006.

21. Ellis KM, O'Carroll DC, Lewis MD, Rychkov GY and Koblar SA. Neurogenic potential of dental pulp stem cells isolated from murine incisors. Stem Cell Res Ther 5: 30, 2014.

22. Wang X, Sha XJ, Li GH, Yang FS, Ji K, Wen LY, Liu SY, Chen L, Ding Y and Xuan K. Comparative characterization of stem cells from human exfoliated deciduous teeth and dental pulp stem cells. Arch Oral Biol 57: 1231-40, 2012.

23. Morse DR: Age-related changes of the dental pulp complex and their relationship to systemic aging. Oral Surg Oral Med Oral Pathol 72: 721-745, 1991.

24. Morse DR, Esposito JV and Schoor RS: A radiographic study of aging changes of the dental pulp and dentin in normal teeth. Quintessence Int 24: 329-333, 1993.

25. Mitsiadis TA, De Bari C and About I: Apoptosis in developmental and repair-related human tooth remodeling: a view from the inside. Exp Cell Res 314: 869-877, 2008.

26. Tranasi M, Sberna MT, Zizzari V, D'Apolito G, Mastrangelo F, Salini L, Stuppia L and Tetè S: Microarray evaluation of age-related changes in human dental pulp. J Endod 35: 1211-1217, 2009.

27. Huang GT, Sonoyama W, Chen J and Park SH: In vitro characterization of human dental pulp cells: various isolation methods and culturing environments. Cell Tissue Res 324: 225-236, 2006.

28. Karaöz E, Doğan BN, Aksoy A, Gacar G, Akyüz S, Ayhan S, Genç ZS, Yürüker S, Duruksu G, Demircan PC, et al: Isolation and in vitro characterisation of dental pulp stem cells from natal teeth. Histochem Cell Biol 133: 95-112, 2010.

29. Lindroos B, Mäenpää K, Ylikomi T, Oja H, Suuronen R and Miettinen S: Characterisation of human dental stem cells and buccal mucosa fibroblasts. Biochem Biophys Res Commun 368: 329-335, 2008. 
30. Choi MR, In YH, Park J, Park T, Jung KH, Chai JC, Chung MK, Lee YS and Chai YG: Genome-scale DNA methylation pattern profiling of human bone marrow mesenchymal stem cells in long-term culture. Exp Mol Med 44: 503-512, 2012.

31. Zaim M, Karaman S, Cetin G and Isik S: Donor age and long-term culture affect differentiation and proliferation of human bone marrow mesenchymal stem cells. Ann Hematol 91: 1175-1186, 2012.

32. Pruszak J, Ludwig W, Blak A, Alavian K and Isacson O: CD15, CD24 and CD29 define a surface biomarker code for neural lineage differentiation of stem cells. Stem Cells 27: 2928-2940, 2009.

33. Breau MA, Pietri T, Eder O, Blanche M, Brakebusch C, Fässler R, Thiery JP and Dufour S: Lack of betal integrins in enteric neural crest cells leads to a Hirschsprung-like phenotype. Development 133: 1725-1734, 2006.

34. Fuchs BC, Fujii T, Dorfman JD, Goodwin JM, Zhu AX, Lanuti M and Tanabe KK: Epithelial-to-mesenchymal transition and integrin-linked kinase mediate sensitivity to epidermal growth factor receptor inhibition in human hepatoma cells. Cancer Res 68: 2391-2399, 2008

35. Miller FD: Riding the waves: neural and nonneural origins for mesenchymal stem cells. Cell Stem Cell 1: 129-130, 2007.

36. Hall PE, Lathia JD, Miller NG, Caldwell MA and Ffrench-Constant C: Integrins are markers of human neural stem cells. Stem Cells 24: 2078-2084, 2006.
37. Aanismaa R, Hautala J, Vuorinen A, Miettinen S and Narkilahti S: Human dental pulp stem cells differentiate into neural precursors but not into mature functional neurons. Stem Cell Discovery 2: 85-91, 2012.

38. Sasaki R, Aoki S, Yamato M, Uchiyama H, Wada K, Okano T and Ogiuchi H: Neurosphere generation from dental pulp of adult rat incisor. Eur J Neurosci 27: 538-548, 2008.

39. Arthur A, Rychkov G, Shi S, Koblar SA and Gronthos S: Adult human dental pulp stem cells differentiate toward functionally active neurons under appropriate environmental cues. Stem Cells 26: 1787-1795, 2008.

40. d'Aquino R, Graziano A, Sampaolesi M, Laino G, Pirozzi G, De Rosa A and Papaccio G: Human postnatal dental pulp cells co-differentiate into osteoblasts and endotheliocytes: a pivotal synergy leading to adult bone tissue formation. Cell Death Differ 14: 1162-1171, 2007.

41. Laino G, d'Aquino R, Graziano A, Lanza V, Carinci F, Naro F, Pirozzi G and Papaccio G: A new population of human adult dental pulp stem cells: a useful source of living autologous fibrous bone tissue (LAB). J Bone Miner Res 20: 1394-1402, 2005.

42. Laino G, Graziano A, d'Aquino R, Pirozzi G, Lanza V, Valiante S, De Rosa A, Naro F, Vivarelli E and Papaccio G: An approachable human adult stem cell source for hard-tissue engineering. J Cell Physiol 206: 693-701, 2006. 